\title{
Das questões fundantes do discurso à instância da política: uma síntese de múltiplas determinaçõ̃es
}

\section{HELSON FláMO da SILVA SOBRINHO \\ Doutor em Linguística pela Faculdade de Letras da Universidade Federal de Alagoas. Professor da graduação emLetras e do Programa de Pós- Graduação emLetras e Linguística - PPGLL- FALE - UFAL. Pesquisador do Grupo de Estudos emDiscurso e Ontologia (Gedon).}

Resumo: Neste artigo, desenvolvernos uma reflexão teórica ancorada na perspectiva do materialismo histórico, trazendo a categoria Trabalho enquanto categoria fundante do ser social (MARX; LUKÁCS). Assumimos a posição teónica que articula a AD coma perspectiva ontológica manxista, retomando Marx e também seguindo os passos de Lukács, para intervir emquestões fundantes no que diz respeito à produção do discurso, entendido como práxis, emque os sentidos se produzemnas práticas de sujeitos, em decorrência de seus envolvimentos sociais, históricos e ideológicos.É a partir dessa perspectiva teórica que são analisados os processos de recontextualização e mistificação presentes nos discursos das propagandas govemamentais acerca da reforma universitánia, especificamente, noProUni (Programa Universidade para Todos) e no Reuni (Programa de Apoio a Planos de Reestruturação e Expansão das Universidades Federais).

Palavras-chave: Discurso. Política. Ideologia. Determinações sociais.
Me do Socorro A. de O. Cavalcante

Doutora emLinguística pela Faculdade de Letras da Universidade Federal de Alagoas, professora da graduação emPedagogia e emLetras e dos programas de Pós-Graduação emEducação - PPGE - e emLetras e Linguística - PPGШ - FALE - UFAL Ĺder do grupo de pesquisa: Políticas públicas: história e discurso do PPGE e pesquisadora do Grupo de Estudos emDiscurso e Ontologia (Gedon).

Abstract: This paper develops a theoretical reflection rooted in the perspective of the Historical Materialismwhile approading human labour as a founding category of the social being (Marx; Lukács). The study takes as a theoretical standpoint the articulation of Discourse Analysis with the Manxist ontological perspective, considering Marx and following Lukács' footsteps so as to intervene with foundational issues regarding the production of discourse, therein understood as praxis where meaning is produced in the subjects' practices in the course of their social, historical and ideological involvement Built over the scaffolding of these authors' contributions, this analysis examines the processes of recontextualization and mystification present in govermment advertisements about university reform specifically ProUni (University for all) and ReUni (support programfor the restructuring and expansion of the federal universities).

Keywords: Discourse. Politics. Ideology. Social determinations. 



\section{Introdução: umaquestão defundamento}

Iniciaremos nossa reflexão trazendo a categoria Trabalho enquanto categoria fundante do ser social (MARX; LUKÁCS). Para nós, uma questão de ordem prática e teórica, pois se trata de uma tentativa de não tangenciar nem margear problemas importantes e/ou questões polêmicas e conflituosas. Entendemos viver num momento de enfrentamentos teóricos e metodológicos decisivos, com implicações políticas derivadas das determinações socioeconômicas, haja vista a crise do capital e a existência de vários discursos que procuram insistentemente denegar essa crise. Assim, o risco de continuarmos em lugares de feições "confortáveis", acreditando que o real é "inalcançável" e/ou "impossível", tem, em última instância, implicações sérias na práxis social. Estamos, pois, não apenas comprometidos, mas instados a enfrentar questões de fundo teórico, metodológico, político e econômico na Análise do Discurso de linha pecheuxtiana no Brasil, ou seja, na AD de nosso tempo e espaço histórico.

Já dissemos em outras oportunidades (SILVA SOBRINHO, 2007; FLORÊNCIO et al, 2009) que é preciso tomar posição pela/na Análise do Discurso e que nossa opção se coloca na articulação da AD com a perspectiva ontológica marxiana, retomando $\mathrm{Marx}$ e também seguindo os passos de Lukács para intervir com questões fundantes no que diz respeito à produção do discurso e ao movimento/desdobramento dos efeitos de sentidos. Queremos neste artigo reafirmar essa tomada de posição, não apenas porque também consideramos a AD uma disciplina de entremeio (ORLANDI, 1999), mas, sobretudo, porque nas práticas científicas e políticas nunca estamos totalmente "livres" de produzir/reproduzir/ transformar e, dialeticamente, de sofrer os efeitos das determinações sócio-históricas.

A A nálise do Discurso, como sabemos, articula 0 linguístico ao sócio-histórico ideológico, e seu objeto de 
${ }^{1}$ Segundo Pêcheux e Fuchs, "[...] a região da ideologia deve ser caracterizada por uma materialidade específica articulada sobre a materialidade econômica: mais particularmente, 0 funcionamento da instância ideológica deve ser concebido como 'determinado em última instância' pela instância econômica, na medida em que aparece como uma das condições (não econômicas) da reprodução da base econômica, mais especificamente das relações de produção inerentes a esta base econômica" (1997, p. 165).

estudo - o discurso - é entendido como práxis, em que os sentidos se produzem nas práticas de sujeitos, como decorrência de seus envolvimentos sociais, históricos e ideológicos. Nessa perspectiva, o discurso é um modo de se pôr formas específicas de ideologia, uma vez que toda prática social implica o desenvolvimento de um conjunto de ideias, valores, crenças e representações acerca de nossa existência histórica. Isso possibilita a configuração de uma "lógica", seja ela tida (interpretada) como "estabilizada" e/ou "não estabilizada", que direciona as práticas sociais, nos seus mais variados campos de atuação, como, por exemplo, no campo da religião, filosofia, ciência, política, direito, educação, artes, que são determinadas, em última instância, pelas relações econômicas ${ }^{1}$.

Isso é algo tão complexo que para produzir um conhecimento objetivo e crítico sobre qualquer discurso faz-se necessário di recionar o ol har aos embates, agitações, conflitos históricos e ideológicos das classes sociais na atualidade. Como diz Pêcheux (2002, p.56):

Todo discurso é o índice potencial de uma agitação nas filiações sócio-históricas de identificação, pois ele constitui ao mesmo tempo um efeito dessas filiações e um trabalho (mais ou menos consciente, deliberado, construído ou não, mas, de todo modo, atravessado pelas determinações inconscientes) de deslocamento no seu espaço.

O discurso é efeito e trabalho nas relações sociais, e "[...] todo processo discursivo se inscreve numa relação ideológica de classes" (PÊCHEUX, 1997, p. 92). Por isso, tomar as condições de produção de existência histórica dos sujeitos possibilita compreender como se dá a inscrição da língua na História, ou seja, trata-se de apreender os discursos a partir de seus funcionamentos nas práticas materiais determinadas. Entretanto, a categoria marxista ontológica trabalho, fundante do ser social, tem sido deixada de lado na Teoria Materialista 
do Discurso, o que nos faz ressaltar que no presente artigo não temos o intuito de "resgatar" uma categoria, mas ir às raízes das questões fundantes, ou seja, como diz M arx (1977), ser radical. ${ }^{2}$

Expliquemos com mais profundidade essa radicalização, reportando-nos à citação de Marx (1985, p. 149), abaixo, pois ela é esclarecedora sobre o que entendemos por trabalho no sentido ontológico:

Antes de tudo, o trabalho é um processo entre 0 homem e a Natureza, um processo em que 0 homem, por sua própria ação, medeia, regula e controla seu metabolismo com a Natureza. Ele mesmo se defronta com a matéria natural como uma força natural. Ele põe em movimento as forças naturais pertencentes à sua corporalidade, braços e pernas, cabeça e mão, a fim de apropriarse da matéria natural numa forma útil para sua própria vida. Ao atuar, por meio desse movimento, sobre a Natureza externa a ele e ao modificá-la, ele modifica, ao mesmo tempo, sua própria natureza.

Fazer referência ao trabalho como categoria fundante do Ser Social permite compreender o lugar do discurso não apenas em nossa prática analítica, mas, sobretudo, nas práticas dos sujeitos em suas diversas instâncias e posição ideológica e política. É certo que sempre partimos do discurso, porém o fundamento último da questão que envolve a produção de sentidos e seus efeitos é o trabalho em seu caráter ontológico, que funda a sociabilidade. É ele, o trabalho, que diferencia o homem da natureza e historiciza os sentidos atribuídos à existência humana, pois é a partir da transformação da natureza (relações homem-natureza) que suas mediações (relações dos homens entre si) se articulam à totalidade social complexa e dinâmica, garantindo a reprodução/ transformação. ${ }^{3} \mathrm{O}$ trabal ho funda a sociabilidade humana e, por isso, é o portador de suas determinações. 0 discurso é um complexo mediador entre a troca orgânica dos
2 "A teoria é capaz de apoderar-se das massas quando argumenta e demonstra ad hominem, e argumenta e demonstra quando se torna radical; ser radical é tomar as coisas pela raiz. M as a raiz, para o homem, é o próprio homem" (M ARX, 1977, p. 8).

3 “Na visão do marxismo, o metabolismo entre homem e natureza é permanente. Cada vez mais el e se distancia da naturezae cada vez mais ele se torna histórico, social, produto da sua própria história, da sua própria atividade. $M$ as ele não tem condição, ao limite, de romper com a naturalidade. Sempre haverá um gancho na natureza. [... ] Civilização é progressivo afastamento do natural, contudo não há um rompimento absoluto em nenhum momento, nem este rompimento é possível. M as há uma transfiguração absoluta. De modo que não há nada no homem que seja puramente natural" (CHASIN, s/d, p. 12). 
homens com a natureza e dos sujeitos entre si (forças produtivas e relações de produção).

É a partir da atuação do homem sobre a natureza e da construção de relações que el es estabelecem entre si, na produção, que se desenvolve a sociabilidade. Assim, as relações sociais assumem uma complexidade ainda maior, dando origem a outros complexos que, apesar de serem fundados pelo trabalho, não se reduzem a ele, mas irão atuar de modo desigual e contraditório na reprodução/ transformação do ser social. Ainda segundo Marx (1996, p. 52),

[...] na produção social da própria vida, os homens contraem relações determinadas, necessárias e independentes de sua vontade, relações de produção estas que correspondem a uma etapa determinada de desenvolvimento das suas forças produtivas materiais. A totalidade dessas relações de produção forma a estrutura econômica da sociedade, a base real sobre a qual se levanta uma superestrutura jurídica e política, e à qual correspondem formas sociais determinadas de consciência. $\mathrm{O}$ modo de produção da vida material condiciona o processo em geral de vida social política e espiritual. Não é a consciência dos homens que determina o seu ser, mas, ao contrário, é o seu ser social que determina sua consciência.

É nesse sentido que a perspectiva materialista parte das determinações da concretude histórica do sujeito efetivo no seu devir humano. Por isso, não se trata de "determinismo econômico", de caráter mecanicista do velho materialismo. Ao contrário, embora o processo das práticas sociais forme uma totalidade complexa e articulada, as mudanças e transformações sociais não são lineares, uma vez que as relações de produção e as forças produtivas entram em contradição no decorrer do desenvolvimento histórico.

É com esse entendimento que podemos dizer que o ser social faz história. É no modo como os sujeitos 
produzem sua vida que se estrutura a base da sociedade e se configura a subjetividade humana com os discursos e as práticas ideológicas. Conforme explicitam M arx e Engels (1998, p. 18): “A produção das ideias, das representações e da consciência está, a princípio, direta e intimamente ligada à atividade material e ao comércio material dos homens; ela é a linguagem da vida real". Isso indica que há um nexo complexo entre pensamento, linguagem e sociabilidade. Não se trata de um nexo mecânicoeconomicista, mas de constatar que esses processos têm sua gênese ontológica na esfera do trabalho. ${ }^{4}$ Isso significa que estamos tomando a linguagem como um complexo mediador na constituição do Ser Social, mas não como fundante deste ser, pois:

Pode-se distinguir os homens dos animais pela consciência, pela religião ou por tudo o que se queira. No entanto, eles próprios começam a se distinguir dos animais logo que começam a produzir seus meios de existência, e esse salto é condicionado por sua constituição corporal. Ao produzirem seus meios de existência, os homens produzem, indiretamente, sua própria vida material. (MARX; ENGELS, 2004, p. 44 - grifos do original).

M esmo que ao nascerem os sujeitos se deparem com um mundo repleto de sentidos que "naturalizam" o social, apresentando um jogo contraditório entre a aparência e a essência, entre a evidência e a opacidade, tudo que está ao nosso redor é resultado da prática sóciohistórica dos sujeitos. Isso acontece porque o ser social não é um ser isolado e abstrato, porém sofre as consequências do seu existir/atuar num determinado momento do desenvolvimento material da sociedade, sendo, ao mesmo tempo, produtor e produzido. ${ }^{5}$ A forma pela qual os homens estabelecem determinadas relações entre si e com a natureza determina a configuração das relações sociais, sejam elas de dominação e conflitos ou não.
${ }^{4}$ Estamos tomando a linguagem como um complexo mediador na constituição do Ser Social, mas não como fundante deste ser, pois "Pode-se distinguir os homens dos animais pela consciência, pela religião ou por tudo o que se queira. No entanto, eles próprios começam a se distinguir dos animais logo que começam a produzirseus meios de existência, e esse salto é condicionado por sua constituição corporal. A o produzirem seus meios de existência, os homens produzem, indiretamente, sua própria vida material" (MARX; ENGELS, 2004, p. 44 - grifos do original).

\footnotetext{
${ }^{5} \mathrm{~V}$ ale ressal tar que " $\mathrm{A}$ ontologia marxiana afasta daquel a de $\mathrm{H}$ egel todo elemento lógicodedutivo e, no plano da evolução histórica, todo elemento teológico. Com esse ato materialista de 'repor sobre os próprios pés', não podia deixar de desaparecer igualmente, da série dos momentos motores do processo, a síntese do elemento simples. Em M arx, o ponto de partida não é dado nem pelo átomo (como nos velhos
} 
materialistas), nem pelo simples ser abstrato (como em Hegel). A qui, no plano ontológico, não existe nada análogo. Todo existente deve ser sempre objetivo, ou seja, deve ser sempre parte (movente e movida) de um complexo concreto. I sso conduz a duas consequências fundamentais. Em primeiro lugar, o ser em seu conjunto é visto como um processo histórico; em segundo, as categorias não são tidas como enunciados sobre algo que é ou que se torna, mas sim como formas moventes e movidas da própria matéria: 'formas do existir, determinações da existência"' (LUKÁCS, 1978, p. 2-3).

${ }^{6}$ Segundo Lukács (1978), o homem é um ser que responde.
Tendo em vista que a História aparece como resultado das práticassociais, torna-sebastante complicado praticar análise do discurso sem levar em consideração a raiz do fazer e fazer-se dos homens, pois estes, ao satisfazerem suas necessidades, criam mais necessidades, tanto materiais como espirituais, que precisam ser atendidas. Desse modo, constroem-se historicamente, dando respostas novas às demandas de sua existência, não repetindo como os animais atos fixados pela natureza, isto porque a forma de ser dos homens resulta das relações materiais que el es praticam. ${ }^{6} \mathrm{D}$ aí que toda formação social é transitória e se transforma pelas contradições geradas pelos atos humanos dentro da própria sociabilidade. No entanto, como lembra Marx (1974), a história (como resultado das práticas sociais) se realiza sob condições materiais determinadas, ou seja, embora os homens produzam sua própria existência, esta só se realiza sob condições concretas de possibilidades.

Assim, podemos considerar que as tentativas de abordar a linguagem e o mundo que não historicizam tais relações perdem de vista a articulação constitutiva entre linguagem e práticas históricas, negando a própria gênese da linguagem enquanto mediação necessária entre os sujeitos. A nosso ver, a linguagem também possui um estatuto ontológico e, por isso, sua base se acha nas relações sociais, como dizem M arx e Engels (1998, p. 24):

A linguagem é tão antiga quanto a consciência, a linguagem é a consciência real, prática, que existe também para os outros homens, que existe, portanto, também primeiro para mim mesmo e, exatamente como a consciência, a linguagem só aparece com a carência, com a necessidade dos intercâmbios com os outros homens.

Como consequência do que expomos, é preciso ressaltar que o discurso possui fundamentos históricos. Se o discurso é uma mediação entre os sujeitos, o tipo de relações históricas que el es estabelecem na produção 
material da própria vida não deve ser desprezado na compreensão da produção e efeitos de sentidos. De acordo com Lukács (1997, p. 64), "[...] o sentido é socialmente construído pelo homem para o homem, para si e para os seus semelhantes; na natureza é uma categoria que não existe de modo al gum, portanto, nem mesmo como sua negação".

Assim, reconhecemos que o sentido nasce das relações entre os sujeitos em suas práticas sociais. Portanto, na natureza ele não existe, já que é apenas nas relações entre os seres sociais que se configura e se complexifica o processo dinâmico e contraditório da produção de sentidos. Todo discurso é entrelaçado na complexa processualidade histórica; sem ela, a produção de sentido seria estável e fechada, ou mesmo não existiria, pois são essas relações que garantem o caráter processual dos efeitos de sentido, implicando movimentos, desdobramentos e transformações.

Voltemos, no entanto, a Pêcheux (1997). Na introdução de sua grande obra, Semântica e Discurso, este autor se refere às questões da unidade da língua $\mathrm{e}$ da divisão discursiva. Seu funcionamento na sociedade capital ista pode ser constatado:

[...] na base econômica, no próprio interior das condições materiais da produção capitalista: necessidades da organização do trabalho, da mecanização e da estandardização que impõem uma comunicaçâo sem equívocos - clareza 'lógica' das instruções e diretivas, propriedade dos temas utilizados, etc. - comunicação que é, ao mesmo tempo, através da divisão social-técnica do trabalho, uma não-comunicação que separa os trabalhadores da organização da produção e os submete à 'retórica' do comando (PÊCHEUX, 1997, p. 26- grifos do original).

Essa citação de Pêcheux é essencial para aprofundar nossa reflexão, porquanto permite pensar a relação da língua com as relações de trabal ho e, também, lançar questões de 
${ }^{7}$ Essa assertiva de Marx trata do método, pois no processo investigativo é preciso partir do real, mas também retornar ao real ecompreendêlo em sua síntese de múlti plas determinações. ordem teórica e metodológica, bem como política, para a A nálise do Discurso (AD), em busca do concreto, ou como diria $M$ arx, da "síntese de muitas determinações, isto é, da unidade do diverso" (M ARX, 1996, p. 39). ${ }^{7}$

O momento daanálisecompreen deacomplexidade do sujeito e a práxis social em sua historicidade. Daí uma das necessidades de nos posicionarmos na Teoria $M$ aterialistado Discurso e tomarmoscomo pressuposto que o sujeito é produtor e também produto da H istória. Desse modo, podemos também compreender que as práticas discursivas conflitantes têm sua gênese no processo de sociabilidade em que o sujeito se autoconstrói, ou seja, se autodetermina na práxis social, enquanto ser que faz história e se diferencia da natureza, pois, dialeticamente, essas mesmas práticas discursivas, em seus efeitos de retorno, também interferem no real sócio-histórico.

N esse ponto, é preciso destacar que a subjetividade não tem existência autônoma e que todo discurso é determinado, em última instância, pela objetividade das relações sociais. A ssim, para compreender o discurso não se pode ficar na aparência (manifestação) fenomênica do real. Embora essa "aparência" faça parte da totalidade complexa da processualidade histórica, não podemos tomá-la em lugar da essência dinâmica e contraditória do real sócio-histórico, pois ficar na aparência do discurso tem implicações sérias, visto que as práticas discursivas e as relações sociais de reprodução/transformação são uma totalidade complexa em constante movência.

Para Pêcheux (1997, p. 255), "O real existe, necessariamente, independentemente do pensamento e fora dele, mas o pensamento depende, necessariamente, do real, isto é, não existe fora do real". Quando aproximamos essa citação do pensamento de Marx (1996, p. 52) - "O modo de produção da vida material condiciona o processo em geral de vida social política e espiritual. Não é a consciência dos homens que determina o seu ser, mas, ao contrário, é o seu ser social que determina sua consciência" 
-, somos convocados a ultrapassar a imediaticidade de todo discurso, ou seja, seu efeito de transparência, já que os sentidos são regidos (determinados) pela processualidade histórica. Isso não significa que tais sentidos em sua aparência fenomênica sejam tidos como irreais e/ou ilusórios. Ao contrário, são materializações da ideologia, pois se os discursos e sua produção de sentidos fossem transparentes e destituídos de contradições, não haveria necessidade de existir uma A nálise do Discurso a buscar, na articulação do discurso com suas condições de produção, ir além da transparência/aparência e do efeito de naturalização do sentido. Este é o caráter essencial da AD: articular o dizer e as suas condições de produção, sendo esta uma questão de fundamento ontológico.

\section{Odiscurso esurs ancoragens histónicas: processos derecontextualizaçãoe mistificação}

Há um mito teórico e político que afirma o "fim das ideologias" na sociedade capitalista. Seus efeitos propalados em todas as sociedades são paradoxais. Qual seria nossa tomada de posição quanto à análise dessas discursividades? Neste momento, trataremos especificamente de dois campos que consideramos inseparáveis: política e educação. ${ }^{8}$

Assumimos com Freire (1996) que toda ação educativa é essencialmente política, pois tem uma intencionalidade e não se dá num vazio conceitual, mas sim direcionada por um modelo teórico de sociedade, tendo por objetivo a manutenção e/ou conservação de determinadas relações sociais. Isso ocorre porque, sendo um fenômeno que se dá no âmbito da sociabilidade, 0 objeto úl timo da educação é a sociedade, e sua ação sempre estará voltada para a conservação ou transformação de um determinado modelo, de acordo com a correl ação de forças políticas e ideológicas, em permanente confronto no seio dessa mesma sociedade. ${ }^{9}$
${ }^{8}$ Segundo Tonet: "O ato educativo, ao contrário do trabalho, supõe uma relação não entre um suje to e um objeto, mas entre um sujeito e umobjeto queé ao mesmo tempo também sujeito. Trata-se, aqui, de uma ação sobre uma consciência visando induzi-la a agir de determinada forma. (2005, p. 218).

${ }^{9}$ Segundo Freire, a educação possui essas duas faces, pois se trata de um modo de intervenção no mundo "Intervenção que além do conhecimento dos conteúdos bem ou mal ensinados e/ ou aprendidos implica tanto o esforço de reproduçãoda ideologia dominante quanto 0 seu desmascaramento. Dialética e contraditória, não poderia ser a educação só uma ou só a outra dessas coisas. Nem apenas reprodutora nem apenas desmascaradora da ideologia dominante" (FREIRE, 1996, p. 98 grifos do original). 
Assim sendo, a classe social que além do poder econômico também detém o controle do poder político, através do Estado, sempre utiliza a educação para realizar (pelo menos em grande parte) seus objetivos. Logo, toda prática educativa é uma prática política e tem como função intervir nas relações sociais, sendo o discurso um instrumento dessa prática. A esse respeito, escreve Henry (1992, p. 24): "[...] com isso não se quer dizer que o político se limita ao campo do discurso, no entanto, dele não pode prescindir, uma vez que o político, como todo fenômeno atinente ao discurso, é uma construção da realidade".

Como já dissemos anteriormente (CAVALCANTE, 2007), o discurso político instaura uma relação específica entre a linguagem e a instituição. Nessa relação, suas formas enunciativas representam a instituição no discurso, legitimando ou deslegitimando o universo social em que se inscreve. Assim, a atividade política pode também ser definida como uma luta não só pela tomada e manutenção do poder, mas pela tomada e manutenção da palavra. Por isso, a conquista da mídia tem sido hoje uma prioridade da política, pois não basta apenas ocupar os canais de comunicação, mas também conquistar a legitimação midiática e fechar 0 acesso aos adversários, impondo seus consensos e valores.

No discurso político, trava-se, pois, uma luta entre dois polos de posições ideológicas heterogêneas. De um lado, a luta pela estabilização dos discursos oficiais/institucionais, veiculados pela imprensa oficial, pela propaganda oficial. Esses discursos materializamse em um conjunto de textos jurídicos e didáticopedagógicos veiculadores de um consenso dominante. Ao tempo que lutam pela sua estabilização, investem na desestabilização de discursos que "precisam" ser controlados/apagados - os discursos contestatórios, que veiculam dissensos de toda ordem.

Para atingir seus objetivos e mascarar/ocultar seu comprometimento com determinados grupos, esse 
discurso lança mão de vários mecanismos discursivos que produzem "excelentes" resultados ideológicos, por sua capacidade de obstaculizar ou mesmo anular a reflexão crítica. Dentre esses mecanismos tomaremos aqui os recursos denominados recontextualização e mistificação. V ejamos o que dizem Silva e Gentilli (1996, p. 167) sobre o processo de recontextual ização:

As categorias linguísticas, os conceitos, ao constranger e limitar a esfera do possível, ao permitir ou impedir que certas coisas sejam pensadas, são parte central de qualquer projeto político. Assim sendo, nenhum processo de obtenção de hegemonia política pode dispensar uma transformação radical dos significados, dos conceitos através dos quais a realidade adquire sentido e pode ser nomeada. Nesse processo, novos conceitos são criados, enquanto outros têm seu significado radicalmente transformado ganhando novas e (in)esperadas inflexões ou sendo, simplesmente deslocados.

O u seja, o processo de recontextual ização consiste na reincorporação de termos em novos contextos, reconfigurando e ressignificando discursos de Formações Discursivas e Ideológicas oponentes, atribuindo-lhes sentidos radicalmente higienizados e transformados. As Formações Ideológicas são expressão da estrutura ideológica de uma formação social que põe em jogo práticas associadas às relações de classe e constituem matrizes de sentido, comuns a um conjunto de discursos que expressam posições assumidas pelos sujeitos, em diferentes práticas sociais concretas. ${ }^{10} \mathrm{~A}$ ssim, expressões que na perspectiva da classe trabalhadora têm um sentido, na perspectiva da ideologia do capital adquirem sentidos opostos e antagônicos. Isso pode ser constatado quando, na defesa da reforma do Estado brasileiro, criticava-se o Estado de Bem-Estar Social, atribuindo a esse modelo a crise por que passava a sociedade brasileira, à época, e defendendo seu ajuste à nova realidade do mercado
${ }^{10}$ Segundo Pêcheux, "Chamaremos, então, formação discursiva aquilo que, numa formação ideológica dada, a partir de uma posição dada numa conjuntura dada, determinada pelo estado da luta de classes, determina o que pode $e$ deve ser dito (articulado sob a forma de uma arenga, de um sermão, de um panfleto, de uma exposição etc.) (1997, p. 160 - grifos do original). 
internacional, que exige a redução do poder estatal, o corte nos gastos públicos, a supressão de direitos adquiridos, agora considerados privilégios.

Quanto ao processo de mistificação, valemo-nos de $V$ oese (1998), que considera esse processo como uma das principais estratégias da ideologia dominante. Diz 0 referido autor:

A mistificação é uma ação que leva o dito a assumir 'status' de al go posto e indiscutível. [...] A presenta uma versão de um fato ou de um fenômeno, mas apaga, estrategicamente, o caminho andado na formação dessa que dificulta a compreensão de sua lógica. [...] ela constroi determinados conceitos, mascara o processo de elaboração e, assim, impedindo uma desconstrução crítica, cria um efeito extremamente poderoso de quase fazer passar como definitivo aquilo que não é (VOESE, 1998, p. 127).

Também consideramos de grande relevância 0 posicionamento de M észáros (1993, p. 10) a esse respeito:

Deve-se enfatizar que o poder da ideologia dominante é indubitavelmente enorme, não só pelo esmagador poder material e por um equivalente arsenal político-cultural à disposição das classes dominantes, mas sim, porque esse poder ideológico só pode prevalecer graças à posição de supremacia da mistificação, através da qual os receptores potenciais podem ser induzidos a endossar, 'consensualmente', val ores e diretrizes práticas que são, na real idade, totalmente adversos a seus interesses vitais. (Grifos do original)

Para entender esses processos de mistificação e recontextualização que sustentam o discurso político é necessário recorrer aos pressupostos teóricometodológicos da Análise do Discurso. Essa perspectiva teórico-metodológica e política fornece subsídios que permitem desvelar os discursos, visto que não se limita, 
apenas, a interpretar fatos na sua aparência fenomênica, mas busca entender esses fatos pela via da conjuntura histórico-ideológica que possibilita o seu surgimento. A $A D$ descreve e interpreta como os sentidos se constituem e se "fixam" e/ou se "deslocam" e atuam na sociedade, sempre na articulação indissociável entre a língua e a História, ou seja, toma as Condições de Produção do discurso como categoria básica de suas análises.

As Condições de Produção, como fundamento necessário a uma análise, podem ser concebidas como amplas ou estritas, expressando tanto as relações de produção, em sua carga sócio-histórico-ideológica (amplas), como as condições imediatas (estritas) que engendram a sua formulação (ORLANDI, 1999). As condições de produção levam, pois, ao entendimento de como os sentidos do discurso se constituem e interferem na realidade, como transformação ou estabilização do sentido "pretendido".11 Elas possibilitam compreender como os acontecimentos significam e afetam os sujeitos em suas diferentes posições político-ideológicas na sociedade, como se organiza o poder, distribuindo posições de subordinação/resistência, de adesão/rejeição etc. ${ }^{12}$

Cabe, pois, ao analista de discurso mostrar, na concretude dos processos discursivos, como se estrutura essa relação entre o singular, o particular e o universal, ou ainda, como se dá a articulação entre a objetividade e a subjetividade, na qual a linguagem atua como mediadora. Um processo histórico movido por contradições, tornando a língua um complexo em si que acolhe todas as manifestações da vida humana, dandolhes uma configuração capaz de comunicá-las e/ou não comunicá-las. Essa referência ao singular, ao particular e ao universal coloca o discurso como objeto mediador de sujeitos concretos e únicos em situações irrepetíveis, em relação à universalidade das relações sociais.

Os discursos das propagandas governamentais acerca da reforma universitária, especificamente ProUni
${ }^{11^{\prime}} \mathrm{V}$ ale ressaltar que para Pêcheux essa possibilidade de o sujeito selecionar seus dizeres para produzir efeitos está submetida a uma Formação Discursiva que rege 0 que se pode ou não ser dito, mas o sujeito sempre se esquece das causas que o determinam ao utilizar "[...] um enunciado, forma ou sequência, e não um outro, que, no entanto, está no campo daquilo que poderia reformulálo na formação discursiva considerada" (PÊCHEUX, 1997, p. 173- grifos do original).

${ }^{12}$ Segundo Bakhtin (1986), os sentidos do discurso são determinados pela situação social mais imediata, que, por sua vez, resulta da conjuntura social mais ampla. 
(Programa Universidade para Todos) e Reuni (Programa de Apoio a Planos de Reestruturação e Expansão das Universidades Federais),que tomaremos como objeto de estudo, são particularidades que expressam posições políticas e ideológicas de um grupo social dominante. $\mathrm{Os}$ sentidos que os referidos discursos articulam não estão somente nas palavras, nos textos, mas na relação que eles estabelecem com a exterioridade, nas condições em que são produzidos, a saber: a adoção do neoliberalismo como base político-ideológica de reorganização do modo de produção capitalista. Nesse contexto, os países que comandam a economia em nível mundial passam a impor aos países tidos como emergentes e/ou em desenvolvimento a necessidade de reformas políticas e econômicas condizentes com seus princípios, pressupostos e fins.

A educação, por sua vez, não poderia ser excluída dessas determinações, pois constitui uma das formas mais eficazes de inculcação ideológica e de veiculação do discurso político (MÉSZÁROS, 2005). Como já foi dito anteriormente, o discurso político se caracteriza pela persuasão e tem como objetivo o mascaramento da realidade, a fim de ganhar a adesão pública e intervir eficazmente nas práticas sociais. É, pois, nesse contexto de reformas políticas e econômicas que é redefinido o sistema nacional de ensino - da pré-escola à pós-graduação. Trata-se de um compl exo de ajustes na educação movidos pela ideologia de mercado, ideologia da flexibilização, da desregulamentação e da privatização.

A qui, trataremos especificamente da reforma universitária que teve início no primeiro mandato do Presidente Luiz Inácio da Silva, Lula. Segundo Bastos (2007, p. 18), já no ano de 2003, através de decreto presidencial,

[...] foi criado Grupode Trabalho Interministerial (GTI), composto da seguinte forma: Ministério da Educação; Casa Civil da Presidência da 
República; Secretaria-Geral da Presidência da República; Ministério do Planejamento, Orçamento e Gestão; Ministério da Ciência e Tecnologia e o M inistério da Fazenda. De acordo com o respectivo decreto o GTI tinha como função 'analisar a situação atual e apresentar plano de ação visando à reestruturação, desenvolvimento e democratização das Instituições Federais de Ensino Superior - IFES'. De acordo com o documento elaborado pelo $\mathrm{GTI}{ }^{13}$, teriam como função, 'sugerir ideias para enfrentar a crise atual das universi dades federais e orientar o processo de reforma da universidade brasileira'. (grifos do original)

Além disso, o governo desenvolveu uma intensa propaganda através dos principais meios de comunicação, com cartazes e panfletos distribuídos em todo o país, bem como a organização do seminário (Universidade: por quee como reformar? ${ }^{14}$ ). A inda segundo o referido autor (2007, p.19), ao lado desses encaminhamentos, foram expedidas medidas provisórias que posteriormente se tornaram projetos de lei. Em especial, "[...] as PPP (Parcerias Público-Privadas); a Lei de Incentivo à Inovação e à Pesquisa Científica e Tecnológica, SINAES ${ }^{15}$, Lei no 10.861, de 2004,que regulamenta as fundações e o ProUni (Programa Universidade Para Todos) - Lei no 11.096 de 2005" e, posteriormente, o Reuni. Aqui, abordaremos 0 ProUni e o Reuni.

Quanto ao ProUni, diz a supracitada Lei:

SD1: Fica instituído o Programa Universidade para todos - ProUni - destinado à concessão de bolsas de estudo integrais e de bolsasparciais (meia bolsa) para cursos de graduação e sequenciais [...] em instituiçôes privadas de ensino superior, com ou sem fins lucrativos. (grifos do original)

Como podemos constatar, o Programa destinase, exclusivamente,às instituições privadas de Ensino Superior ("com ou sem fins lucrativos") e consiste
${ }^{13}$ Disponível em: http:// www.anped.org.br/ reformauniversitaria3. pdf

${ }^{14}$ Promovido pela SeSu/ MEC - Secretaria de Educação Superior e pelas Comissões de Educação do Senado e da Câmara dos Deputados, Brasília, em 6 e 7 de agosto de 2003, durante a gestão do ex-ministro da educação Cristovam Buarque.

${ }^{15}$ Sistema Nacional de A valiação do Ensino Superior. 
na compra de vagas ociosas dessas instituições para alunos que não conseguem ingressar nas Universidades públicas, nem têm recursos para financiar um curso pago. Daí o investimento de recursos públicos em instituições privadas de ensino. Segundo Bastos e Florêncio (2005, p. 66),

$$
\begin{aligned}
& \text { Essa estratégia desenvolvida pelo governo } \\
& \text { visa a construir uma imagem progressista } \\
& \text { da reforma do ensino superior, onde dentre } \\
& \text { outras coisas, o ingresso nas universidades } \\
& \text { particulares é apresentado como uma das grandes } \\
& \text { saídas para a educação superior. [...] A ideia é } \\
& \text { apresentar o ensino superior como bem público, } \\
& \text { desvinculando a questão do público do âmbito } \\
& \text { estatal e englobando o privado, atribuindo-lhe } \\
& \text { uma suposta 'responsabilidade social'. }
\end{aligned}
$$

Esse entendimento fica evidente na Lei nº 11.096 de 2005, que estabelece:

$S D$ 2: as universidades deverão ser instituições públicas, sejam elas de propriedade pública ou privada. A universidade não pode morrer por falta de recursos públicos nem pode recusar os recursos privados de quem nela quer investir. (grifos nossos)

Ressignifica-se e recontextualiza-se o sentido de público - não mais o que é estatal e gratuito, mas tudo que é "ofertado ao público"-, restando silenciado (ORLANDI, 1999) que esse público terá de pagar pelo bem "ofertado". É possível perceber também uma ameaça - a "universidade não pode morrer por falta de recursos públicos" -, ou seja, el a poderá morrer à míngua, se depender apenas dos recursos públicos, cada vez mais reduzidos. Para que isso não ocorra, ela "não pode recusar os recursos privados de quem nela quer investir". Com Orlandi, podemos destacar que "Se, ao dizer, nos significamos e significamos o próprio mundo, ao mesmo tempo, a realidade se constitui nos sentidos que, enquanto sujeitos, praticamos. É dessa 
maneira que a linguagem é uma prática. Não no sentido de efetuar atos, mas porque pratica sentidos, intervém no real" (ORLANDI, 1999, p. 95), ou seja, todo dizer tem implicações no real.

Argumentam alguns "ingênuos": "Mas agindo assim, o governo não está democratizando o acesso à universidade, possibilitando, aos que não podem pagar um curso superior, o acesso a esse nível de ensino?". Certamente, os usuários desse programa também 0 consideram uma benesse do governo. Como contrapor um discurso contestatório a essa proposta que, à primeira vista, parece atender a uma bandeira de luta defendida pelo movimento estudantil da década de 1960, que clamava por democratização da Universidade pública? Consideramos pertinente a contribuição de Courtine (2006, p. 21) quando, ao falar sobre "a arte da mentira política", diz que para levar a bom termo esse projeto ambicioso, certas condições são imprescindíveis: "É necessário dispor de uma massa de crédulos prontos a repetir, expandir, disseminar por toda parte as falsas notícias que foram forjadas por outros. A reserva de ingênuos é indispensável, pois, 'não há homem que recite e espal he uma mentira com tanta graça como aquele que acredita nela'".

O discurso do ProUni, ao passar a ideia de que está democratizando 0 acesso à universidade e possibilitando a "inclusão", nesse nível de ensino, de um contingente de alunos até então excluídos, é recebido com euforia por uma "massa de crédulos" e "ingênuos" que o entendem como a salvação dos excluídos. Com isso, além de desqualificar os discursos contestatórios - que criticam essas reformas -, mascara o compromisso do governo em socorrer as instituições privadas de ensino, mediante a compra de vagas ociosas. Além disso, apaga/silencia o total descaso do governo com relação ao ensino público de nível fundamental e médio, uma das razões por que os alunos das escolas públicas, que não podem ter acesso 
ao ensino pago, não têm acesso à Universidade Pública mais concorrida e, ainda, de melhor qualidade.

Além do ProUni, no âmbito de ajuste do ensino superior às recomendações de organismos financeiros internacionais, outro golpe é desferido contra a Universidade pública: - o Reuni, Programa de Reestruturação Universitária. Enquanto o ProUni é destinado apenas às instituições privadas de ensino superior, o Reuni destina-se, exclusivamente, às Universidades públicas e tem por objetivo:

SD3: Criar condições para ampliaçãodo acesso e permanência na educação superior, no nível de graduação, utilizando-se do melhor aproveitamento da estrutura fisica e dos recursos humanos atualmente existentes. (Grifos nossos)

O Reuni foi implantado no governo Lula, entretanto, comparando seu objetivo com o Plano estratégico para a educação superior, do governo FHC 1995/1998, verificamos que eles estão em perfeita consonância.

$S D$ 4: Expandir o sistema de ensino superior público, por meio da otimização dos recursos disponíveis e da diversificação do atendimento, valorizando alternativas institucionais aos modelos existentes. (Grifos nossos).

Como podemos constatar, as duas sequências grifadas (SD3 e SD4) explicitam a mesma recomendação de como deverá acontecer a "ampliação"|"expansão" do ensino superior: "utilizando-se do melhor aproveitamento da estrutura física e dos recursos humanos atualmente existentes"/"por meio da otimização dos recursos disponíveis."Ou seja, a expansão do ensino superior deverá ocorrer sem nenhum investimento além do que já existe, bastando aproveitar "melhor" a estrutura física e os recursos humanos atual mente existentes.

As escolhas lexicais "melhor aproveitamento"e "otimizaçâo" possibilitam a leitura de um não dito que 
está implícito - a estrutura física e os recursos humanos existentes são suficientes, apenas não estão sendo bem aproveitados. Isso equivale a afirmar que as universidades públicas possuem estrutura física e recursos humanos ociosos. Donde se infere que melhor aproveitamento da estrutura física é aumento de alunos em sala de aula; otimização dos recursos humanos é sobrecarga do trabalho do professor e aumento de horas- aula, aumento de alunos por turma, aumento "quantitativo" da produção acadêmica. ${ }^{16}$

Esse discurso está em consonância com 0 discurso neoliberal de reestruturação produtiva que atrela a educação a interesses empresariais e gerenciais, vinculando-a a conceitos como produtividade, otimização de recursos e redução de custos. Segundo Pêcheux (1997, p. 26), “[...] aquilo que hoje é tendencialmente 'a mesma língua', no sentido linguístico desse termo, autoriza funcionamentos de 'vocabulário-sintaxe' e de 'raciocínios' antagonistas". Compreende-se, portanto, que esse discurso estatal é um discurso paradoxal, do "fazer mais com menos", também presente no Plano Nacional de Educação - PNE: “[...] Há que se pensar em racionalização de gastos e diversificação do sistema. [...] $O$ setor público poderá, sem gastos adicionais, atender a um número maior de estudantes". (Grifos nosso).

Afinada a esse discurso da "racionalização de gastos e diversificação do sistema"está a política de "diversificação do atendimento, valorizando alternativas institucionais aos modelos existentes." Na prática, diversificação do atendimento significa substituição do regime presencial pela educação a distância de precária qualidade; valorizar "al ternativas institucionais aos modelos existentes", bem como destruição do tripé ensino/pesquisa/extensão, criando universidades "só de ensino" e alguns centros de excelência que poderão desenvolver pesquisas.

Retomemos Courtine (2006), que, ao falar sobre "a nova arte da mentira política", diz que George Orwell

\footnotetext{
${ }^{16}$ Segundo Pêcheux, os processos ideológicos simulam os processos científicos: "[...] o sistema da línguaé, de fato, o mesmo para o materialista e para o idealista, para 0 revolucionário e para o reacionário, para aquele que dispõe de um conhecimento dado e para aquele que não dispõe desse conhecimento. Entretanto, não se pode concluir, a partir disso, que esses diversos personagens tenham o mesmo discurso" (1997, p. 91- grifos do original).
} 
"[...] percebeu claramente na sua época a fabricação da mentira". Courtine se refere a escritos de Orwell sobre a guerra civil espanhola, quando o referido autor, que combateu na Espanha, pela causa socialista, narra suas experiências. É de George Orwell (1970, p. 166, apud Courtine, 2006, p. 23) a citação que segue:

Vilas sem defesa sucumbem aos bombardeios aéreos, seus habitantes são dispersos nos campos, o gado é morto, as cabanas são destruídas pelas chamas incendiárias: é a isto que se denomina pacificação. Milhões de camponeses são despojados de suas roças e largados ao longo das estradas, levando aquilo que podem carregar como única bagagem: é a isso que se denomina transferência de população ou retificação de fronteiras.

Percebemos, na citação do autor, os mecanismos discursivos a que nos referimos anteriormente - a recontextualização e a mistificação. $O$ conceito de "pacificação" é convocado para justificar a destruiçãoo provocada pelos ataques; o de "retificação de fronteiras", para justificar a expulsão dos camponeses de seus campos e a expropriação de seus bens.

Esses mesmos mecanismos discursivoideológicos se fazem presentes nos discursos da reforma da educação superior brasileira (ProUni/ Reuni). Parafraseando Orwell, podemos dizerque 0 desvio de verbas públicas para financiar instituições privadas de ensino denomina-se: "ProUni"; o processo de expansão desordenada do ensino superior, que sucateia a universidade pública e implode o tripé ensino/pesquisa/extensão denomina-se "Reuni".

\section{Considerações finais: umretomo às questões fundantes}

Se, como diz Pêcheux (1997), conhecimento científico e prática política não estão dissociados, ao 
contrário, são domínios essencialmente articulados, para nós, a Análise do Discurso - mesmo em seu caráter acadêmico, científico e institucionalizado - não é uma prática direcionada a um fim em si mesmo. Tratase, isso sim, de uma prática científica e, sobretudo, política. Por isso a compreensão do discurso deve estar voltada à transformação e não à reprodução das relações opressoras. Como afirma Pêcheux, "[...] os objetos ideológicos são sempre fornecidos concomitantemente com a maneira de se servir deles, com a pressuposição de seu 'sentido', quer dizer, também com sua orientação' (1990, p. 12- grifos do autor). Por tudo isso, não se deve temer o discurso, mas anali isá-lo para compreen der como ele materializa as práticas ideológicas, e, em seu caráter material, intervém no movimento de reprodução/ transformação do real sócio-histórico.

A pesar disso, compreender o real e encontrar possibilidades de intervenção parece ser hoje o nosso grande "(im)possível". Nesse sentido, trata-se de uma questão de fundamento ontológico, e isso exige que a perspectiva materialista não seja abandonada na AD. É que o funcionamento do discurso se processa em uma particularidade histórica, a envolver silêncios, não ditos, movimento de paráfrase e polissemia, metáfora, recontextualização e mistificação de sentidos, ou seja, um "trabalho" do discursivo-ideológico de recobrimento-reprodução-reinscrição e de "efeitos" paradoxais na história. Isso exige uma tomada de posição efetiva, de radical crítica à (des)ordem burguesa e suas discursividades dissimuladas/dissimuladoras da crueldade do sistema capitalista. Essa postura não é apenas uma tarefa teórica e/ou metodológica, mas, sobretudo, uma questão de prática transformadora. 


\section{Referências}

BAKHTIN, Mikhail. Marxismo e Filosofia da Linguagem:

Problemas fundamentais do método sociológico na ciência da linguagem. 3.ed. São Paulo: Hucitec, 1986.

BASTOS, Alexandre; FLORÊNCIO, Tatiana. O (dis)curso da reforma universitária no Brasil. In CAVALCANTE, Ma. do Socorro (Org.). As malhas de discursos (re) veladores. Maceió: Edufal, 2005.

BASTOS, Alexandre. A reforma da universidade no Brasil: um discurso (re)velador. M aceió: Edufal, 2007.

CAVA LCANTE, Ma. do Socorro. Qualidade e cidadania nas reformas da educaçâo brasileira. M aceió: Edufal, 2007.

CHASIN, José. O método dialético. Palestra transcrita. Maceió - Ufal, s/d.

COURTINE, Jean-Jacques. 0 mentir verdadeiro. In: SWIFT, Jonathan. $A$ arte da mentira política. Campinas: Pontes, 2006.

FLORENCIO, Ana Gama et al. Análise do discurso:

fundamentos e práticas. M aceió: Edufal, 2009.

FREIRE, Paulo. Pedagogia da autonomia. São Paulo: Paz e Terra, 1996.

HENRY, Paul. A ferramenta imperfeita. Campinas, Ed. Unicamp, 1992.

LUKÁ CS, George. As Bases Ontológicas do Pensamento e da A tividade do Homem. In Temas de Ciências Humanas. Vol. 4, São Paulo, 1978.

LUKÁ CS, George. O Trabalho. Trad. Ivo Tonet.M aceió, 1997. (mímeo). 
M ARX, Karl. Manuscritos econômico-filosóficos. São Paulo: Boitempo, 2004.

M ARX, Karl. Para a crítica da economia política São Paulo: Nova Cultural, 1996.

M ARX, Karl. O Capital. Livro I. 2.ed., São Paulo: Nova Cultural, 1985.

MARX, Karl. Crítica da filosofia do direito de Hegel: introdução. In Temas de Ciências Humanas. v. 2. São Paulo: Grijalbo, 1977.

M ARX, Karl. O 18 Brumário e cartas A. Kugelmam. Rio de Janeiro: Paz e Terra, 1974.

M ARX, Karl; ENGELS, Friedrich. $A$ ideologia Alemã Trad. Luis Cláudio de Castro e Costa. São Paulo: M artins Fontes, 1998.

M ARX, Karl; ENGELS, Friedrich. A ideologia Alemâ Trad. Frank Müller. São Paulo: Martin Claret, 2004.

M ÉSZÁ ROS, István. Filosofia, ideologia e ciência social: ensaios de negação e afirmação. São Paulo: Ensaio, 1993.

MÉSZÁ ROS, István. Educação para além do capital. São Paulo: Boitempo, 2005.

ORLANDI, Eni. Análise de discurso. Campinas: Pontes, 1999.

PÊCHEUX, M ichel. Delimitações, inversões, deslocamentos. In Cadernos de estudos linguísticos, 19. Campinas, SP: Editora da Unicamp, 1990.

PÊCHEUX, Michel. O Discurso: estrutura ou acontecimento. Campinas: Pontes, 2002.

PÊCHEUX, Michel. Semântica e Discurso. Campinas: Editora da Unicamp, 1997.

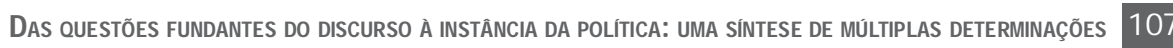


PÊCHEUX, Michel; FUCHS, C. A propósito da análise automática do discurso: atual ização e perspectivas (1975). In: GADET, F.;HAK, T. (orgs.). Por uma análise automática do discurso. Uma introdução à obra de Michel Pêcheux. 3. ed. Campinas ( SP): Editora da Unicamp, 1997.

SILVA SOBRINHO, Helson. Discurso, velhice e classes sociais. M aceió: Edufal, 2007.

SILVA, Tomaz; GENTILLI, Pablo (Orgs.). ESCOLA S. A. Quem ganha e quem perde no mercado educacional do neoliberalismo. Brasília, CNTE, 1996.

TONET, I vo. Educação, cidadania e emancipação humana. Ijuí: Ed. Unijuí, 2005.

VOESE, Ingo. O movimento dos Sem-Terra na imprensa: um exercício de análise do discurso. Ijuí. Ed. Unijuí, 1998.

[Recebido em 10 de junho de 2012

e aceito para publicação em 20 de setembro de 2012] 